\title{
Brine Flow Up a Well Caused by Pressure Perturbation from Geologic Carbon Sequestration: Static and Dynamic Evaluations
}

\author{
Jens T. Birkholzer*1, Jean Philippe Nicot $^{2}$, Curtis M. Oldenburg ${ }^{1}$, \\ Quanlin Zhou ${ }^{1}$, Stephen Kraemer ${ }^{3}$, Karl Bandilla ${ }^{4}$
}

${ }^{1}$ Lawrence Berkeley National Laboratory, University of California, Berkeley, CA 94720

${ }^{2}$ Bureau of Economic Geology, The University of Texas at Austin, Austin, TX 78713

${ }^{3}$ US EPA, Office of Research and Development (ORD), Athens, GA 30605-2700

${ }^{4}$ US EPA, Office of Research and Development (ORD), Athens, GA 30605-2700 (now at Princeton University, Department of Civil and Environmental Engineering, Princeton, NJ 08544)

*Corresponding author: jtbirkholzer@1bl.gov, ph. 510 486-7134

\begin{abstract}
Industrial-scale storage of $\mathrm{CO}_{2}$ in saline sedimentary basins will cause zones of elevated pressure, larger than the $\mathrm{CO}_{2}$ plume itself. If permeable conduits (e.g., leaking wells) exist between the injection reservoir and overlying shallow aquifers, brine could be pushed upwards along these conduits and mix with groundwater resources. This paper discusses the potential for such brine leakage to occur in temperature- and salinitystratified systems. Using static mass-balance calculations as well as dynamic well flow simulations, we evaluate the minimum reservoir pressure that would generate continuous migration of brine up a leaking wellbore into a freshwater aquifer. Since the brine invading the well is denser than the initial fluid in the wellbore, continuous flow only occurs if the pressure perturbation in the reservoir is large enough to overcome the increased fluid column weight after full invasion of brine into the well. If the threshold pressure is exceeded, brine flow rates are dependent on various hydraulic (and other) properties, in particular the effective permeability of the wellbore and the magnitude of pressure increase. If brine flow occurs outside of the well casing, e.g., in a permeable fracture zone between the well cement and the formation, the fluid/solute transfer between the migrating fluid and the surrounding rock units can strongly retard brine flow. At the same time, the threshold pressure for continuous flow to occur decreases compared to a case with no fluid/solute transfer.
\end{abstract}

Keywords: brine leakage, pressure increase, Area of Review 


\section{Introduction}

Geologic carbon sequestration (GCS) has drawn increasing consideration as a promising method to mitigate the adverse impacts of climate change. Subsurface reservoirs being considered for storage of $\mathrm{CO}_{2}$ include saline formation, oil and gas reservoirs, and unmineable coal seams (Baines and Worden, 2004; IPCC, 2005). By far the greatest storage capacity is in saline formations (Dooley et al., 2004), and our discussion will focus primarily on $\mathrm{CO}_{2}$ storage in these. Most issues for safety and security of $\mathrm{CO}_{2}$ storage arise from the fact that, at typical temperature and pressure conditions encountered in terrestrial crust, $\mathrm{CO}_{2}$ is less dense than aqueous fluids. Accordingly, $\mathrm{CO}_{2}$ will experience an upward buoyancy force in most subsurface environments, and will tend to migrate upwards whenever permeable pathways are available (Bachu, 2008; Pruess, 2008a, b; Tsang et al., 2008).

Another potential hazard is that of widespread fluid pressure increase arising from the injection process. Because of the large volumes of $\mathrm{CO}_{2}$ that need to be sequestered for industrial-scale GCS, the zone of elevated pressure during and after injection can extend many kilometers from the injection site, much farther than the $\mathrm{CO}_{2}$ plume itself (e.g., Birkholzer et al., 200). If permeable conduits exist in this zone of elevated pressure, formation brines could be pushed upwards along these conduits and intrude into overlying groundwater resources (e.g., Nordbotten et al., 2004). Recent simulation studies have demonstrated the potentially large scale of pressure perturbation considering hypothetical future $\mathrm{CO}_{2}$ injection scenarios, for simple idealized conditions (e.g., Zhou et al., 2008; Birkholzer et al., 2009) as well as for more complex situations based on real 
groundwater basins (e.g., Nicot, 2008; Yamamoto et al., 2009; Birkholzer and Zhou, 2009; Zhou et al., 2010).

While the regulatory environment for geologic carbon sequestration projects is still evolving, it is clear that one aspect of permitting needs to be the protection of valuable groundwater resources. Because groundwater quality can be affected by intrusion of $\mathrm{CO}_{2}$ (aquifer acidification and possibly mobilization of trace elements) as well as brine (mixing with saline water and co-migrating contaminants) (e.g., Apps et al., 2010; Kharaka et al., 2010), the permitting requirements may include some assessment of the potential for $\mathrm{CO}_{2}$ leakage as well as some assessment of large-scale pressure buildup and associated potential for brine migration. The United States Environmental Protection Agency (USEPA) has recently developed a draft regulation for geologic carbon sequestration under the Safe Drinking Water Act (SDWA), its main focus being the protection of underground sources of drinking water (USDW) from injection-related activities (USEPA, 2008). The proposed rule requires that an Area of Review be defined in which all artificial penetrations that may act as conduits for fluid movement between the injection formation and overlying USDWs (such as improperly abandoned wells) must be identified and, if necessary, corrective action must be taken (e.g., re-plugging of wells, remedial cementing).

The question remains, however, how the size of an Area of Review should be determined in practice. While there is a general consensus that the region of maximum future $\mathrm{CO}_{2}$ plume extent needs to be well characterized (e.g., NETL, 2010), it is not clear at present 
how to handle the much larger region of pressure impact. Can the size of an Area of Review be determined based on a threshold value of pressure buildup and, if so, how should this value be calculated? One possible approach discussed in the United States is based on the existing framework of USEPA's Underground Injection Control (UIC) program, which regulates injection of hazardous and non-hazardous fluids, injection related to oil and gas production, injection related to solution mining operations, and some other types of injection operations. In the UIC program, the Area of Review is either assigned a fixed radius or it is (conservatively) computed as the region where the reservoir pressure increase experienced at any time would be able to lift saline formation water through a potentially existing unplugged well into an overlying freshwater aquifer (USEPA, 2002; Nicot et al., 2008).

Estimates of brine leakage rates as a function of reservoir pressure buildup have been presented by several researchers, for well leakage scenarios involving various degrees of complexity including multiple well and/or multiple aquifer/aquitard systems (e.g., Nordbotten et al., 2004). These are often based on the assumption that brine leakage is independent of salinity variation along the leakage pathway. In salinity-stratified systems, however, a pressure increase in the injection reservoir may not necessarily generate continuous leakage up an unplugged well. As pointed out by Nicot et al. (2008), sustained brine migration may only occur if the actual pressure perturbation exceeds a critical minimum value such that the increased fluid column weight after full invasion of brine into the well can be overcome. Otherwise, brine migration would stop before reaching the freshwater aquifer, and the system would simply attain a new static 
equilibrium. Thus, this critical minimum value, mostly determined by the vertical distance and the initial versus the final density profile in the well, may define a threshold pressure useful for Area-of-Review determination. The Area of Review around a storage project would be defined as the area within which the predicted pressure change from injection exceeds the threshold value at any time during or after injection. Nicot et al. (2008) presented a method for calculating this threshold pressure, based on a static massbalance evaluation of the weight of brine column in the well after full invasion of brine up to the bottom of the freshwater aquifer.

The current paper addresses the same objective of calculating the threshold pressure for sustained brine migration. In addition static mass-balance calculations following Nicot's approach, we employ a non-isothermal flow simulator to model dynamic brine flow in a vertical wellbore surrounded by an idealized layered sequence of formations. The advantage of this approach is that the non-isothermal system dynamics can be considered and that various limiting assumptions inherent in the static calculations can be relaxed. We then compare results from static and dynamic calculations for a range of scenarios and determine whether a static solution is adequate or not. We also utilize the dynamic model to calculate wellbore flow rates and related sensitivities, which cannot be done with a simple static evaluation. The basic setup of the dynamic model for upward brine displacement is similar to a study recently conducted by Oldenburg and Rinaldi (2010).

Figure 1 illustrates the conceptual model of wellbore brine migration utilized for the comparison of static (Section 2) and dynamic solutions (Section 3). An leaking wellbore 
connects a deep $\mathrm{CO}_{2}$ storage reservoir with an overlying freshwater aquifer, with the well being screened in the storage reservoir and open to the aquifer (i.e., the most conservative scenario of a direct hydraulic connection between the storage reservoir and the aquifer). As a result of pressure perturbations from $\mathrm{CO}_{2}$ injection, reservoir brine may enter the wellbore, migrate upward, and then invade the shallow aquifer. Brine flow occurs up the well casing, which is assumed impermeable; thus there is no transfer of fluid and solute between the wellbore and the intervening shale formation. (The same conceptual model would represent the end member case of a borehole without casing embedded in impermeable shale.) For comparison, an alternative scenario is considered in Section 4 (see Figure 8), where brine migrates through a fracture zone outside the well casing. In this scenario, the migrating brine exchanges fluid/solute with the adjacent shale layer, albeit at a small rate. 


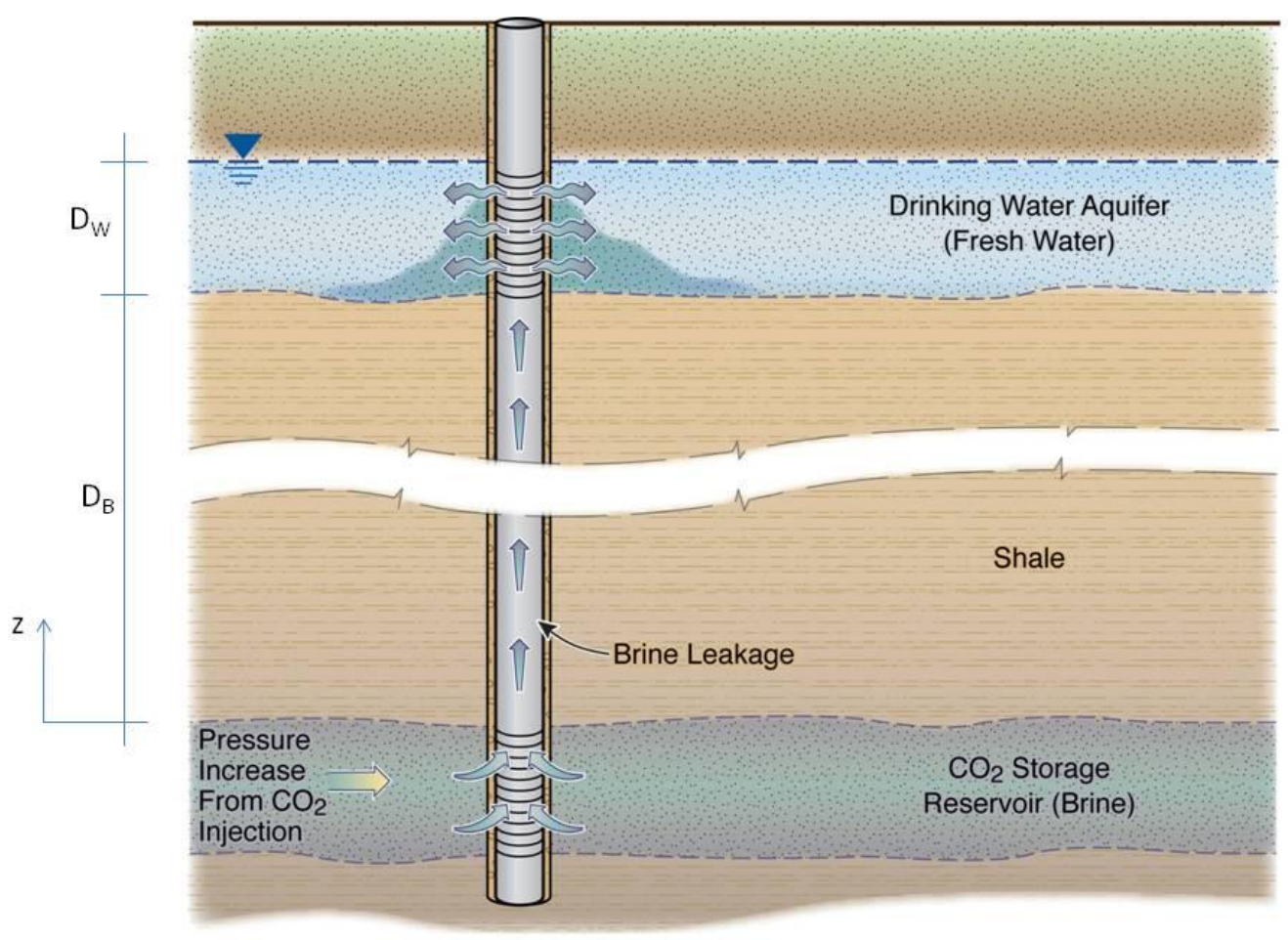

Figure 1: Schematic showing upward brine migration inside an unplugged wellbore caused by pressurization from $\mathrm{CO}_{2}$ injection 


\section{Static Evaluation of Wellbore Brine Migration}

Nicot et al. (2008) presented a static calculation method to determine the critical minimum value of pressure increase sufficient to lift denser brine up an open wellbore to the base of a freshwater aquifer. Below, we briefly review this method and apply the approach, after slight modification, to an example case. The same example case is then considered using a dynamic model as described in Section 3, and differences between static and dynamic evaluations are discussed.

\subsection{Static Calculation Method}

An increase in pressure in the injection formation will lead to the migration of brine into and up the wellbore. However, if the brine is denser than the well fluid it displaces and the pressure increase is below a critical minimum value, upward migration stops before formation brine reaches the bottom of the shallow aquifer. We can calculate the pressure change in the injection formation required to lift denser brine in the wellbore from the top of the injection formation up to the bottom of the shallow aquifer (i.e., the distance $D_{B}$ shown in Figure 1). Sustained flow of brine up the well will occur if the actual pressure change in response to $\mathrm{CO}_{2}$ injection increases to a level larger than this threshold value. Assuming that the initial fluid pressures $P_{B}$ at the top of the injection reservoir and $P_{W}$ at the bottom of the shallow aquifer (both of which are measured near the wellbore) are known, the threshold pressure $\Delta P_{\text {crit }}$ is given by:

$$
\Delta P_{c r i t}=\int_{0}^{D_{B}} \rho_{B}(z) g d z+P_{W}-P_{B}
$$


where $\rho_{B}(z)$ is brine density at depth z (a function of salinity as well as temperature and pressure). The integral in Equation (3.1), which can be easily solved numerically, represents the hydrostatic pressure of the brine column in the well after the injection brine has moved up to the bottom of the shallow aquifer. We use the equation-of-state correlations implemented into the multi-phase multi-component software TOUGH2 (Pruess et al., 1999) to calculate density of brine as a function of salinity, temperature, and pressure.

The static calculation assumes that the wellbore casing is impermeable between $\mathrm{z}=0$ and $\mathrm{z}=\mathrm{D}_{\mathrm{B}}$; i.e., there is no exchange of fluids or salts between the wellbore and the intervening formations. As a result, at and above the pressure threshold, the brine that has invaded the wellbore has uniform salinity equal to the salinity of the injection reservoir. Following Nicot et al. (2008), we consider two bounding cases for critical pressure analysis. The first case, referred to as the equilibrium case, assumes that the invading fluid instantaneously equilibrates with its surroundings, i.e., to an approximately linear pressure profile defined by $P_{W}$ at the top and $P_{B}+\Delta P_{c r i t}$ at the bottom, and to a temperature profile defined by the initial temperature distribution in the formation. In this case, the density of the brine in the wellbore varies slightly as a function of depth. (Note that we perform an approximate calculation of depth-dependent density variation, taking into account the initial pressure and temperature variation, while neglecting the comparably small pressure increase $\Delta P_{\text {crit }}$. ) The second case, referred to as the uniformdensity case, assumes uniform brine density in the wellbore equal to the density in the injection reservoir $\rho_{B}(z)=\rho_{B}(z=0)$. This simplification may be considered adequate 
because the temperature and pressure variation encountered by the migrating fluid has opposite effects on density; the temperature drop from deep to shallow depths will tend to increase brine density, while the pressure drop will tend to decrease brine density, the net effect of both being rather small.

Note that Equation (3.1) is formulated taking into account that the system may not be at hydrostatic equilibrium initially. In the case where $P_{B}$ and $P_{W}$ represent hydrostatic equilibrium, the resulting threshold pressure from Equation (3.1) comprises only the contribution caused by the wellbore being filled with invading brine that is denser than the initial fluid. If the injection formation is initially below hydrostatic, then a larger pressure increase can be sustained. If the injection formation is initially over pressured, the resulting critical pressure threshold value will be smaller than the one calculated for hydrostatic conditions.

\subsection{Example Application}

To illustrate the static calculation and its results, we consider the hypothetical example problem of a wellbore connecting the bottom of a shallow freshwater aquifer with the top of a deep injection reservoir assuming a vertical separation distance $D_{B}=1,400 \mathrm{~m}$. Since the well fluids are in direct hydraulic contact with the freshwater aquifer and the saline reservoir, the initial salinity in the well varies linearly with depth. Two different salinity cases are considered: one with a brine reservoir salinity of $48,000 \mathrm{mg} / \mathrm{L}$ (low-salinity case) and another one with a brine reservoir salinity of $128,000 \mathrm{mg} / \mathrm{L}$ (high-salinity case) (both salinity values are given at the top of the brine reservoir). For comparison with the 
dynamic model in Section 4, the initial salinity value at the bottom of the freshwater aquifer is calculated from linear interpolation between the reservoir salinity and an assumed zero salinity at the top of the freshwater aquifer, which has a saturated-zone thickness of $100 \mathrm{~m}$ in this example (i.e., the distance $D_{W}$ in Figure 1). This gives salinity values of $3,200 \mathrm{mg} / \mathrm{L}$ and $8,533 \mathrm{mg} / \mathrm{L}$ at the bottom of the freshwater aquifer, respectively, for the two reservoir salinity cases. The initial pressure is $1 \mathrm{MPa}(10 \mathrm{bar})$ at the bottom of the freshwater aquifer and $15.28 \mathrm{MPa}(152.8 \mathrm{bar})$ at the top of the brine reservoir. Both values represent hydrostatic conditions; i.e., the calculated threshold pressure is only related to the density increase after brine intrusion into the wellbore, not to initial pressure non-equilibrium. The initial temperature varies linearly with a geothermal gradient of $30^{\circ} \mathrm{C} / \mathrm{km}$, from $18^{\circ} \mathrm{C}$ at the bottom of the freshwater aquifer to $60^{\circ} \mathrm{C}$ at the top of the brine reservoir.

Figure 2 shows the density profiles in the wellbore before and after intrusion of brine. The brine density in the injection reservoir is $1022 \mathrm{~kg} / \mathrm{m}^{3}$ and $1078 \mathrm{~kg} / \mathrm{m}^{3}$ for the lowand the high-salinity cases, respectively. Initially, the density in the wellbore decreases from deep to shallow, primarily caused by the reduction in salinity. The density profile changes after the initial wellbore fluid has been displaced by reservoir brine with uniform salinity of $48,000 \mathrm{mg} / \mathrm{L}$ and $128,000 \mathrm{mg} / \mathrm{L}$, respectively, for the two salinity cases. As mentioned before, two alternative methods are employed for calculating the density profile after brine invasion. The uniform-density calculation assumes that the brine density within the wellbore is equal to the reservoir brine density. The equilibrium calculation considers density variation with depth assuming that the pressure and 
temperature of the invading brine varies linearly between the freshwater aquifer and the brine reservoir.

As shown in Figure 2, the equilibrium calculation features increasing brine density from deep to shallow depths, ranging from $1022 \mathrm{~kg} / \mathrm{m}^{3}$ at the bottom up to $1031 \mathrm{~kg} / \mathrm{m}^{3}$ at the top of the wellbore for the low-salinity case and, respectively, from $1078 \mathrm{~kg} / \mathrm{m}^{3}$ to 1087 $\mathrm{kg} / \mathrm{m}^{3}$ for the high-salinity case. This increase is due to the fact that the thermallyinduced volume reduction of water caused by temperature decrease has a larger effect than the compressibility-induced water expansion caused by pressure decrease. To compare these opposing effects, we present density values varying temperature and pressure separately, here for the low-salinity case. For example, if only the temperature of the brine would vary within the wellbore (from $60^{\circ} \mathrm{C}$ at the bottom to $18^{\circ} \mathrm{C}$ at the top), while pressure and salinity remain equal to reservoir conditions, the fluid density would increase by $14 \mathrm{~kg} / \mathrm{m}^{3}$, from $1022 \mathrm{~kg} / \mathrm{m}^{3}$ at the bottom to $1036 \mathrm{~kg} / \mathrm{m}^{3}$ at the top of the wellbore. In contrast, if only pressure would vary from $15.28 \mathrm{MPa}$ to $1 \mathrm{MPa}$, with temperature and salinity equal to reservoir conditions, the fluid density would decrease by $6 \mathrm{~kg} / \mathrm{m}^{3}$, from $1022 \mathrm{~kg} / \mathrm{m}^{3}$ at the bottom to $1016 \mathrm{~kg} / \mathrm{m}^{3}$ at the top of the wellbore. We may now execute the integral of Equation (3.1) and determine the threshold pressure $\Delta P_{c}$ for the different calculation cases. For the low-salinity case, the threshold pressures calculate to $0.21 \mathrm{MPa}(2.1$ bar $)$ in the equilibrium calculation and $0.13 \mathrm{MPa}(1.3 \mathrm{bar})$ in the uniform-density calculation. Pressure increments in the injection formation higher than these thresholds would push the column of denser brine in the wellbore up to the 
base of the freshwater aquifer and would thereby lead to contamination. Pressure increments lower than this threshold would give rise to partial penetration of brine into the wellbore, but would not result in sustained brine flow. A higher brine salinity leads to larger admissible pressure. For the high-salinity case, we arrive at threshold pressure values of $0.58 \mathrm{MPa}$ (5.8 bar) in the equilibrium calculation and $0.5 \mathrm{MPa}(5.0$ bar) in the uniform-density calculation. A higher initial brine salinity in the injection reservoir corresponds to a smaller Area of Review size, as the threshold pressure is reached closer to the injection well. This is an interesting observation given the fact that in the case of leakage the environmental impact of intrusion of a higher-salinity brine into a freshwater aquifer is more severe.
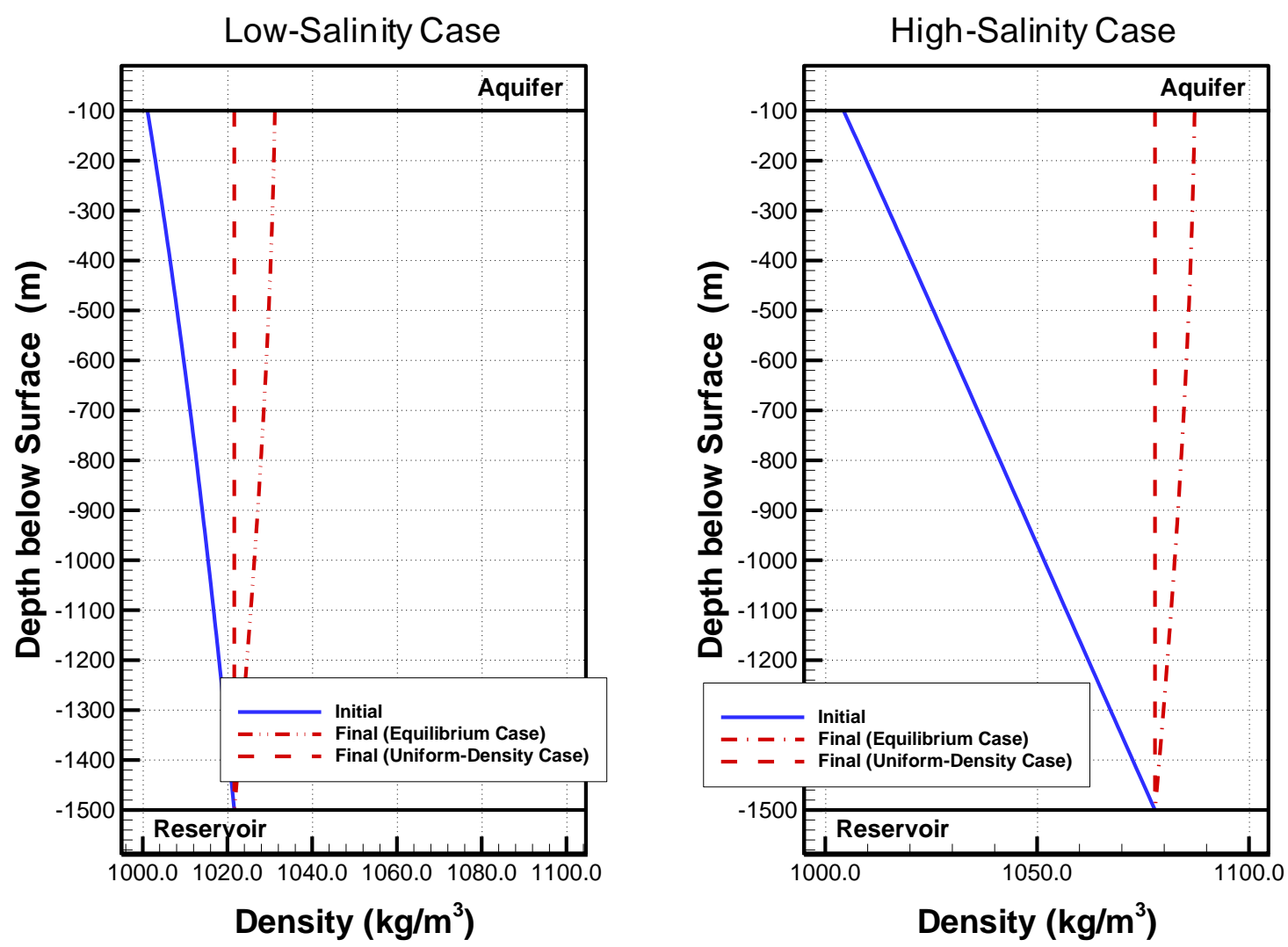

Figure 2: Vertical density profiles before and after invasion of brine. 


\section{Dynamic Simulation of Wellbore Brine Migration}

Dynamic simulations of wellbore brine migration are conducted here for the same example cases as considered in Section 2, involving brine migration up a vertical leaking wellbore surrounded by an idealized layered sequence of formations. The simulations are conducted using the multi-phase multi-component software TOUGH2, utilizing its EOS7 option for non-isothermal transport of water and brine (and optional air) mixtures (Pruess et al., 1999). By running dynamic simulations rather than static calculations, we can address the following research questions:

1) Are the results from the static solutions supported by the simulation results, the latter considering the dynamics of the system and making less stringent assumptions? How accurate are the threshold pressures calculated using the static solutions? Which one of the static solutions is more accurate compared to the dynamic model (e.g., will the denser fluid migrating up the wellbore effectively equilibrate with formation temperature and aquifer pressure)?

2) What are the wellbore flow rates once the threshold pressure is exceeded? What are the controlling parameters? What is the impact of brine intrusion on the shallow aquifer?

The focus in this paper is on the comparison between static and dynamic evaluations (Item 1). We briefly touch on the resulting flow rates as a function of pressure buildup and other key properties, but plan to present a more thorough discussion of wellbore flow rates and potential groundwater impacts in a future publication. 


\subsection{Model Setup}

Similar to the static evaluation example, we consider a system of $1,400 \mathrm{~m}$ vertical separation between a freshwater aquifer and a deep saline storage reservoir connected via a leaking wellbore of given effective permeability. In contrast to the static model, we now need to consider not only the wellbore, but also the aquifer, the reservoir, and the intervening formation(s). We select a thickness of $100 \mathrm{~m}$ for the injection reservoir and a water level of $100 \mathrm{~m}$ in the aquifer, here assumed to be unconfined, and furthermore postulate that the entire intervening strata is comprised of low-permeability shale. The well, which extends through the vertical length of the model domain, is assumed open over the 100-m-thick freshwater aquifer and is perforated over the injection reservoir, while a perfectly functioning casing is assumed between them (i.e., no fluid and diffusive transport exchange between wellbore and the shale, only heat transfer). A radiallysymmetric vertical mesh was developed with considerable grid refinement near the well (horizontal direction) and near formation interfaces (vertical direction) (see Figure 3). The maximum radius of the model domain is $2,000 \mathrm{~m}$.

To evaluate the impact of pressurization related to $\mathrm{CO}_{2}$ storage in the brine formation, the system is subjected to an instantaneous pressure increase along the outer boundary of the radial-symmetric domain (i.e., at $\mathrm{R}=2,000 \mathrm{~m}$ ), imposed over the thickness of the storage reservoir and assumed to be constant over the simulation period. The instantaneous pressure change imposed at the boundary, which represents large-scale pressurization effects from distant $\mathrm{CO}_{2}$ injection, propagates to the well location, causes a slightly delayed pressurization there, and starts pushing dense brine up the wellbore. Note that the 
pressure response at the well location is almost identical in value to the outer boundary pressure change, as a relatively permeable storage reservoir is considered. We conduct simulations for various pressure boundary conditions, ranging from $0.1 \mathrm{MPa}$ to $1.5 \mathrm{MPa}$ pressure increase. Depending on the magnitude of reservoir pressure increase, and the vertical density increase in the wellbore compared to the initial state, the perturbed system either generates sustained brine migration up the well into the shallow aquifer or a new hydrostatic equilibrium forms, in which the well is only partially invaded by brine and further migration stops.

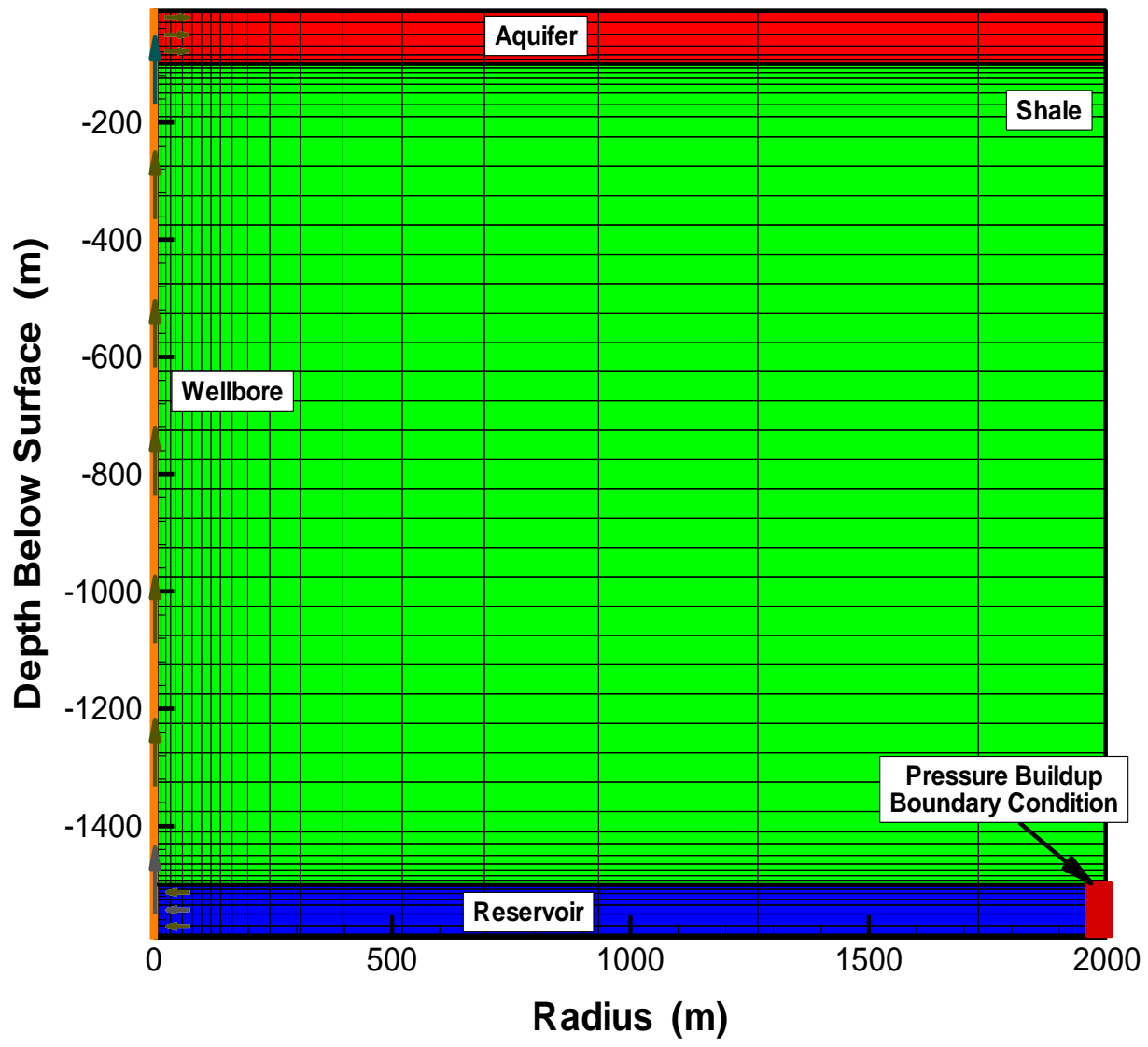

Figure 3: Radial-symmetric model grid for dynamic simulations 
The hydrostatic calculations in Section 2 depend on the vertical distance between the injection formation and the shallow aquifer, and on the initial versus the final density profile in the well (which in turn is a function of salinity, temperature, and pressure variation with depth). The dynamic simulation study conducted here depends on those same properties, but in addition requires definition of various other model inputs such as formation and wellbore hydraulic/thermal properties, and initial as well as boundary conditions. These are summarized in Tables 1 and 2 for the base case simulation. The main assumptions behind some of these model choices are as follows:

- The leaking wellbore is simulated as an equivalent porous medium with a very high permeability and a porosity of 1 . This porous medium approximation is convenient in that it allows the efficient numerical solution with a Darcy-type simulator, but it also reflects the fact that leaking wells are often not completely open conduits, but are rather partially plugged with degraded cement, or may be filled with mud or other debris. We account for this range of possible well conditions by simulating a range of effective wellbore permeability cases. In our base case simulation, we choose an effective permeability value of $10^{-8} \mathrm{~m}^{2}$ (= 10,000 Darcy) along the vertical extent of the wellbore. For comparison, we run additional cases with effective permeabilities of $10^{-6} \mathrm{~m}^{2}, 10^{-10} \mathrm{~m}^{2}$, and and $10^{-12} \mathrm{~m}^{2}$, corresponding to cases with very little to moderate resistance to flow.

- The model domain is initially in hydrostatic equilibrium, which is achieved by running an initial simulation — with closed bottom and lateral boundaries- - to steady state. Similar to the static example, temperature and salinity vary linearly 
with depth, both in the formation and in the wellbore. As pointed out in Nicot et al. (2008), intervening shale layers often have a higher salinity than adjacent sand layers because of differences in groundwater recharge. This effect is not considered in the current simulations, in part to simplify the problem but also in consideration of its limited importance in a setting where the wellbore and the adjacent shale have no interaction except for heat transport.

- The top and bottom boundary conditions in Table 2 represent the top of the aquifer and the bottom of the reservoir, respectively. Boundary condition values for pressure, temperature, and salinity are chosen such that the initial values at the top and bottom of the wellbore are identical to the values selected for the static calculations in Section 3. For example, the top and bottom boundary condition temperatures of $15^{\circ} \mathrm{C}$ and $63^{\circ} \mathrm{C}$ selected for the simulation domain give initial temperatures of $18^{\circ} \mathrm{C}$ and $60^{\circ} \mathrm{C}$ at the top and bottom of the wellbore, respectively, equal to the static calculation. Salinity values of $0 \mathrm{mg} / \mathrm{L}$ at the top and $51,200 \mathrm{mg} / \mathrm{L}$ at the bottom of the model domain correspond to the static calculation low-salinity case with $3,200 \mathrm{mg} / \mathrm{L}$ at the top of the wellbore and $48,000 \mathrm{mg} / \mathrm{L}$ at the bottom of the wellbore. 
Table 1: Base Case Properties of Simulation Cases

\begin{tabular}{|c|c|c|c|}
\hline Parameter & Unit & Value & Comment \\
\hline \multicolumn{4}{|l|}{ All rock units } \\
\hline Porosity & - & 0.3 & \\
\hline $\begin{array}{l}\text { Thermal } \\
\text { Conductivity }\end{array}$ & $\mathrm{W} /(\mathrm{m}-\mathrm{K})$ & 2.51 & \\
\hline Heat Capacity & $\mathrm{J} /(\mathrm{kg}-\mathrm{K})$ & 1,000 & \\
\hline Molecular Diffusion & $\mathrm{m}^{2} / \mathrm{s}$ & $10^{-9}$ & $\begin{array}{l}\text { No molecular diffusion for wellbore } \\
\text { connection with shale }\end{array}$ \\
\hline $\begin{array}{l}\text { Formation } \\
\text { Compressibility }\end{array}$ & $\mathrm{Pa}^{-1}$ & 0 & $\begin{array}{l}\text { Formation compressibility is not } \\
\text { considered in this simple model. }\end{array}$ \\
\hline \multicolumn{4}{|l|}{ Injection Formation } \\
\hline Permeability & $\mathrm{m}^{2}$ & $10^{-12}$ & Isotropic \\
\hline \multicolumn{4}{|l|}{ Shale Formation } \\
\hline Permeability & $\mathrm{m}^{2}$ & $10^{-18}$ & Isotropic \\
\hline \multicolumn{4}{|l|}{ Shallow Aquifer } \\
\hline Permeability & $\mathrm{m}^{2}$ & $10^{-12}$ & Isotropic \\
\hline \multicolumn{4}{|l|}{ Wellbore } \\
\hline Vertical Permeability & $\mathrm{m}^{2}$ & $10^{-8}$ & \\
\hline Lateral Permeability & $\mathrm{m}^{2}$ & $10^{-12}$ & $\begin{array}{l}\text { For wellbore connection with shallow } \\
\text { aquifer and injection formation }\end{array}$ \\
\hline Lateral Permeability & $\mathrm{m}^{2}$ & 0 & For wellbore connection with shale \\
\hline Porosity & - & 1.0 & \\
\hline $\begin{array}{l}\text { Thermal } \\
\text { Conductivity }\end{array}$ & $\mathrm{W} /(\mathrm{m}-\mathrm{K})$ & 2.51 & $\begin{array}{l}\text { For wellbore connection with adjacent } \\
\text { formations }\end{array}$ \\
\hline $\begin{array}{l}\text { Wellbore Cross- } \\
\text { Sectional Area }\end{array}$ & $\mathrm{m}^{2}$ & 0.1 & Assuming a 4-inch wellbore diameter \\
\hline
\end{tabular}

* Note however that brine compressibility is intrinsically taken into account in TOUGH2 in terms of density variation with fluid pressure. At reservoir conditions, brine compressibility is about $3.5 \times 10^{-10}$ $\mathrm{Pa}^{-1}$, which is on the lower end of the range of pore compressibility values reported for well-consolidated sandstones (e.g., Zhou et al., 2010). 
Table 2: Model Initial and Boundary Conditions (Base Case)

\begin{tabular}{|l|l|}
\hline Boundary Conditions & \multicolumn{2}{|l|}{$\begin{array}{l}\text { Fixed Pressure: } \mathrm{P}=\text { atmospheric (unconfined aquifer) } \\
\text { Fixed Temperature: } \mathrm{T}=15^{\circ} \mathrm{C} \\
\text { Fixed Salinity: } \mathrm{S}=0 \mathrm{mg} / \mathrm{L}\end{array}$} \\
\hline $\begin{array}{l}\text { Bottom of Injection } \\
\text { Formation }\end{array}$ & $\begin{array}{l}\text { Closed boundary for fluid and dissolved salt } \\
\text { Fixed Temperature: } \mathrm{T}=63^{\circ} \mathrm{C} \\
\text { Fixed Salinity: } \\
\text { Low-Salinity Case with } \mathrm{S}=51,000 \mathrm{mg} / \mathrm{L}\end{array}$ \\
\hline Top and Bottom of Well & $\begin{array}{l}\text { Closed boundary for fluid, mass, and heat (i.e., wellbore is } \\
\text { assumed to be plugged above shallow aquifer and below } \\
\text { injection formation) }\end{array}$ \\
\hline $\begin{array}{l}\text { Lateral Boundary at } \\
\text { R = 2,000 m }\end{array}$ & $\begin{array}{l}\text { Fixed pressure, temperature, and salinity equal to initial } \\
\text { condition (except within injection formation, where initial } \\
\text { pressures are increased to represent pressure pulse from } \\
\text { storage) }\end{array}$ \\
\hline Initial Conditions & $\begin{array}{l}\text { Thermally stratified system with geothermal gradient of } \\
\text { 30 }\end{array}$ \\
\hline Temperature & $\begin{array}{l}\text { Compositionally stratified system with linear variation of } \\
\text { salinity from top of shallow aquifer (0 mg/L) to bottom of } \\
\text { brine formation }\end{array}$ \\
\hline Salinity & $\begin{array}{l}\text { Hydrostatic equilibrium calculated from running } \\
\text { simulation model to steady state (i.e., considering } \\
\text { temperature, salinity, and density effects on pressure) }\end{array}$ \\
\hline Pressure & $\begin{array}{l}\text { Depends on initial temperature, salinity, and pressure } \\
\text { distribution }\end{array}$ \\
\hline
\end{tabular}




\subsection{Simulation Results}

\subsubsection{Threshold Pressure and Flow Rates}

The pressure increase imposed at the outer boundary of the model domain propagates to the wellbore location and induces brine invasion up the permeable conduit. To evaluate the threshold pressure above which sustained brine flow into the freshwater aquifer occurs, we have conducted a suite of simulations with different pressure increases ranging from $0.1 \mathrm{MPa}$ to $1.5 \mathrm{MPa}$. Figure 4 shows the evolution of flow rates and salinities measured in the open wellbore at the bottom of the shallow freshwater aquifer, for the low-salinity case. Small pressure increases of $0.1 \mathrm{MPa}$ and $0.2 \mathrm{MPa}$ generate a short-term pulse of flow up the well, during which initial well fluids are partially displaced by invading brine. However, as evident from the salinity evolution where the maximum values are much lower than the reservoir salinity, upward migration of reservoir brine stops before reaching the bottom of the shallow aquifer. As the pressure increase is balanced by the increased fluid density in the wellbore, the system attains a new equilibrium and no further flow occurs in the wellbore. The time needed to attain equilibrium depends mostly on the time it takes for the imposed pressure boundary condition to reach the wellbore location. The only fluid leaving the wellbore and entering the freshwater aquifer is the volume of displaced water initially in the well; this volume is small (less than $140 \mathrm{~m}^{3}$ ) and presumably will minimally impact water quality.

In contrast, sustained flow of brine is observed in cases with reservoir pressure increases of $0.3 \mathrm{MPa}$ or more. It appears that the threshold pressure for sustained flow is somewhere between 0.2 and $0.3 \mathrm{MPa}$ in this simulation example. (The static calculation 
arrived at threshold pressure of 0.21 and $0.13 \mathrm{MPa}$ for the equilibrium and uniformdensity assumptions, respectively.) For cases where the threshold value is exceeded only slightly by the reservoir pressure increase, the flow rates feature an early peak followed by a decrease to a constant long-term rate (Figure 4a). The timing of the decrease coincides with higher-salinity water migrating up the wellbore (Figure 4b); the quasistatic long-term rate establishes once the reservoir brine has fully invaded the wellbore. Long-term flow rates range from about $6 \times 10^{-3} \mathrm{~kg} / \mathrm{s}$ (137 gallon per day) for the 3-bar case to about $0.11 \mathrm{~kg} / \mathrm{s}(2,510$ gallon per day) for the 15-bar case.

The 10-bar and 15-bar cases show slowly, but steadily increasing flow rates with time (Figure 4a). This long-term behavior is caused by a gradual increase in the formation temperature near the wellbore as warm brine continues to migrate from depth. The formation temperature increase, in turn, results in less efficient cooling of the migrating fluid, therefore lower fluid density and less column weight, thus less resistance to flow. In all other cases, with less pressure buildup in the reservoir and thus less warm brine migrating upward, the formation temperature increase is too small to have a noticeable effect on the flow rates. 


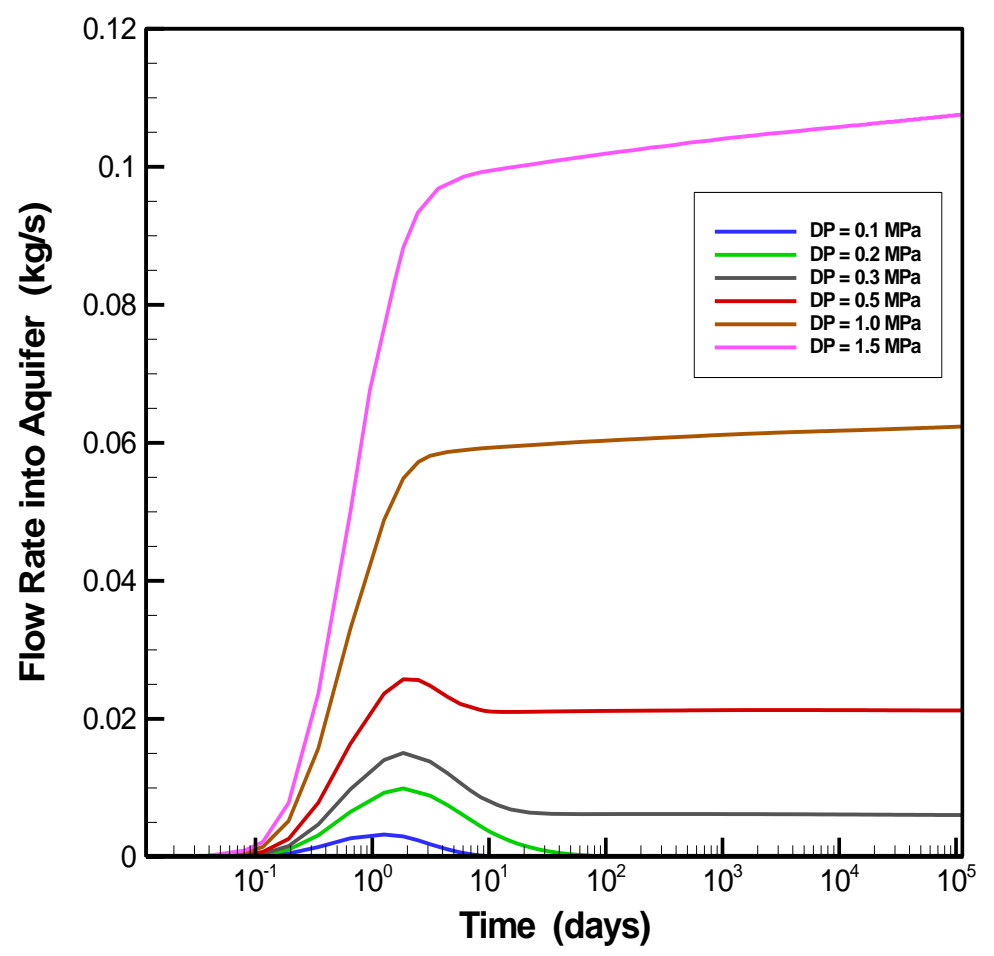

(a)

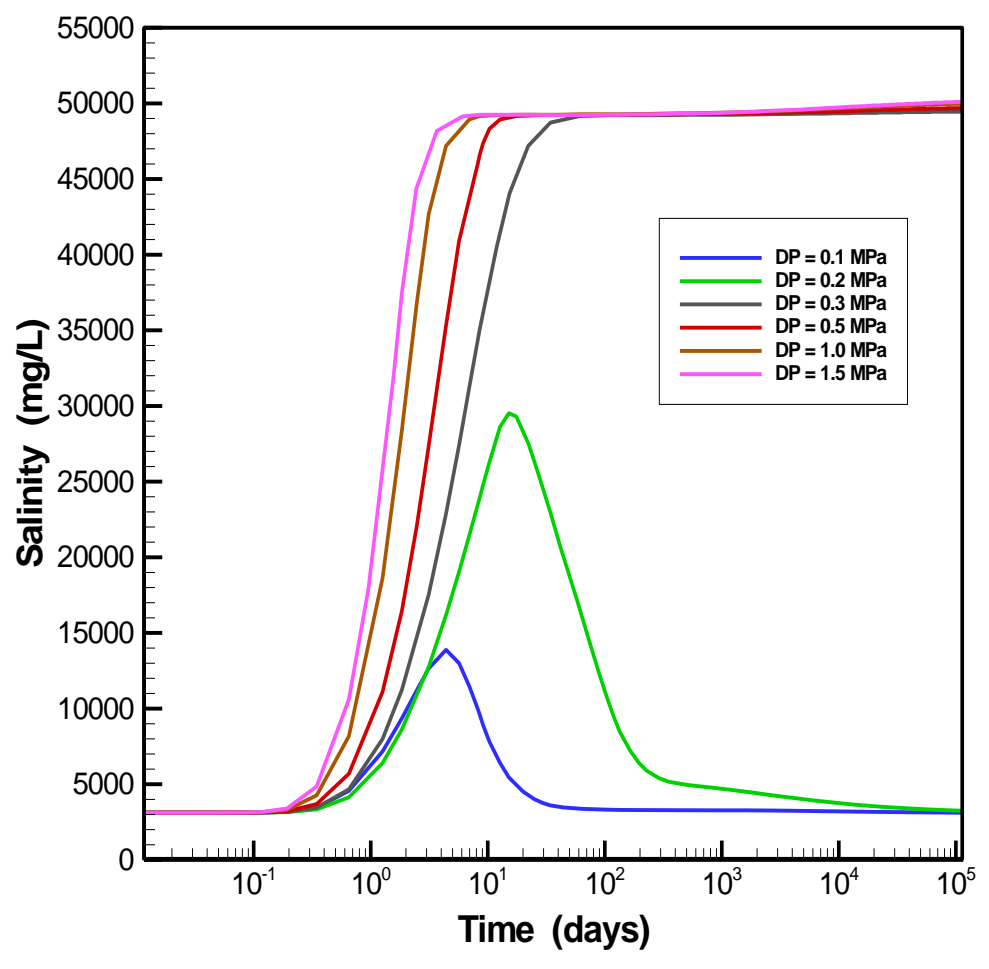

(b)

Figure 4: Evolution of (a) flow rate and (b) salinity in wellbore at the bottom of the freshwater aquifer, for the low-salinity case. DP refers to the pressure increase boundary condition in the brine reservoir. 
In order to establish an estimate of threshold pressure from the dynamic results, we have plotted the quasi-static long-term flow rates as a function of pressure change, for a variety of pressure buildup cases (Figure 5). The flow-rate versus pressure-increase curve suggests that the maximum pressure increase with zero sustained flow is about $0.21 \mathrm{MPa}$ for the low-salinity case and about $0.57 \mathrm{Mpa}$ for the high-salinity case. These threshold values correspond to the static calculation assuming equilibrium of the invading brine with its surroundings, suggesting that this assumption is more realistic than the uniformdensity calculation.

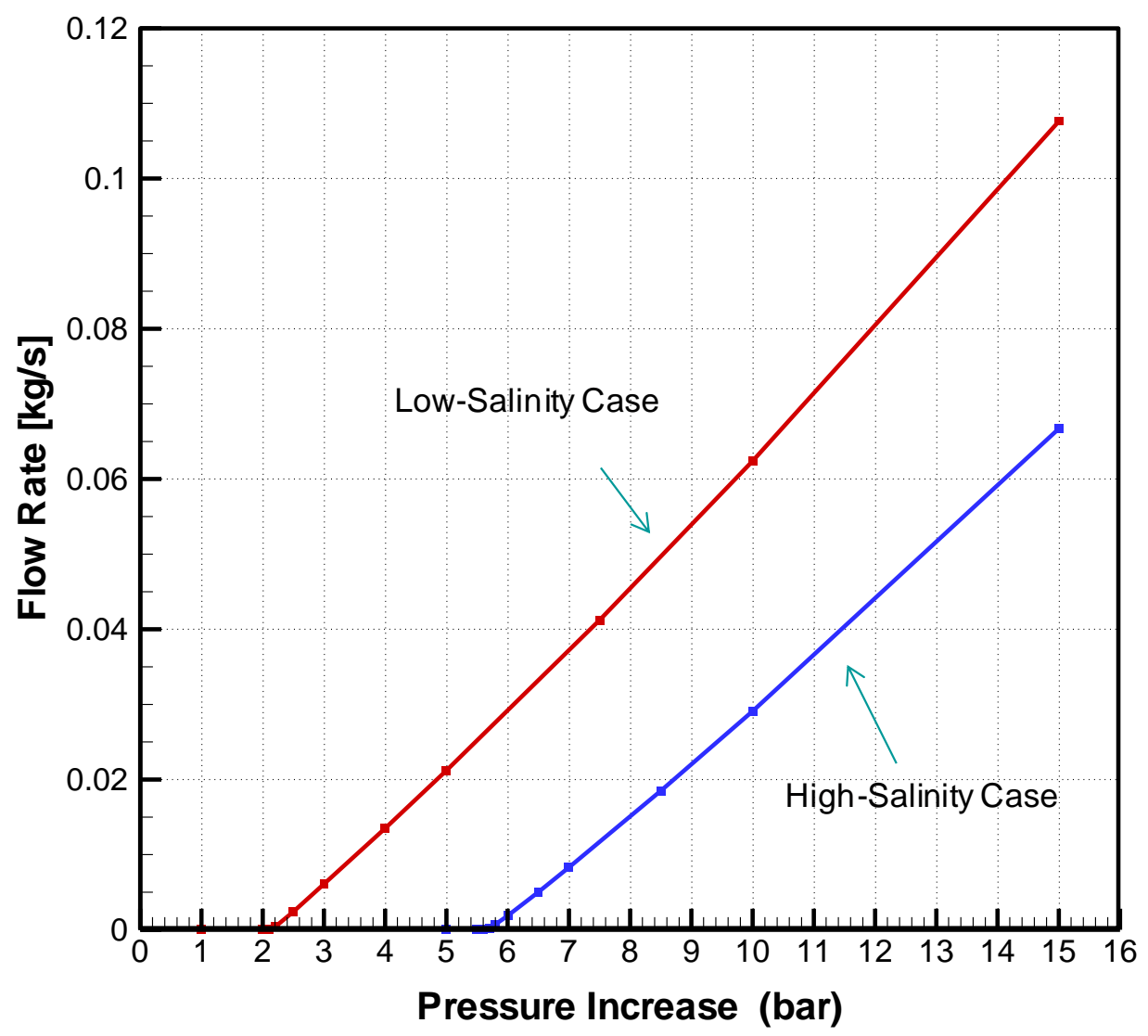

Figure 5: Long-term flow rate as a function of pressure increase in the reservoir. 


\subsubsection{Comparison of Static and Dynamic Solutions}

The density, temperature and pressure profiles in Figure 6 demonstrate that the static model with equilibrium assumption provides a reasonable representation of the wellbore conditions as simulated by the dynamic model. Results from the dynamic model for a pressure increase of $0.5 \mathrm{MPa}$ (where the brine fully invades up the wellbore and sustained flow occurs) compare well with the equilibrium assumption, i.e., the pressure profile is approximately linear, defined by the respective pressure conditions in the freshwater aquifer and the brine reservoir. Also, the temperature profile is similar to the initial temperature distribution in the formation, with non-zero but negligible temperature increase compared to the natural geothermal gradient. Consequently, the density profiles from the static equilibrium calculation and from the dynamic simulation both show increasing brine density from deep to shallow, a behavior clearly different from the static uniform-density case. We may conclude that the equilibrium calculation is the more accurate static methodology for deriving threshold pressure compared to the uniformdensity calculation. The threshold values obtained from the uniform-density method are less precise, but easier to derive (i.e., no depth-dependent changes in brine salinity) and conservative compared to equilibrium values (i.e., the threshold values are smaller). 

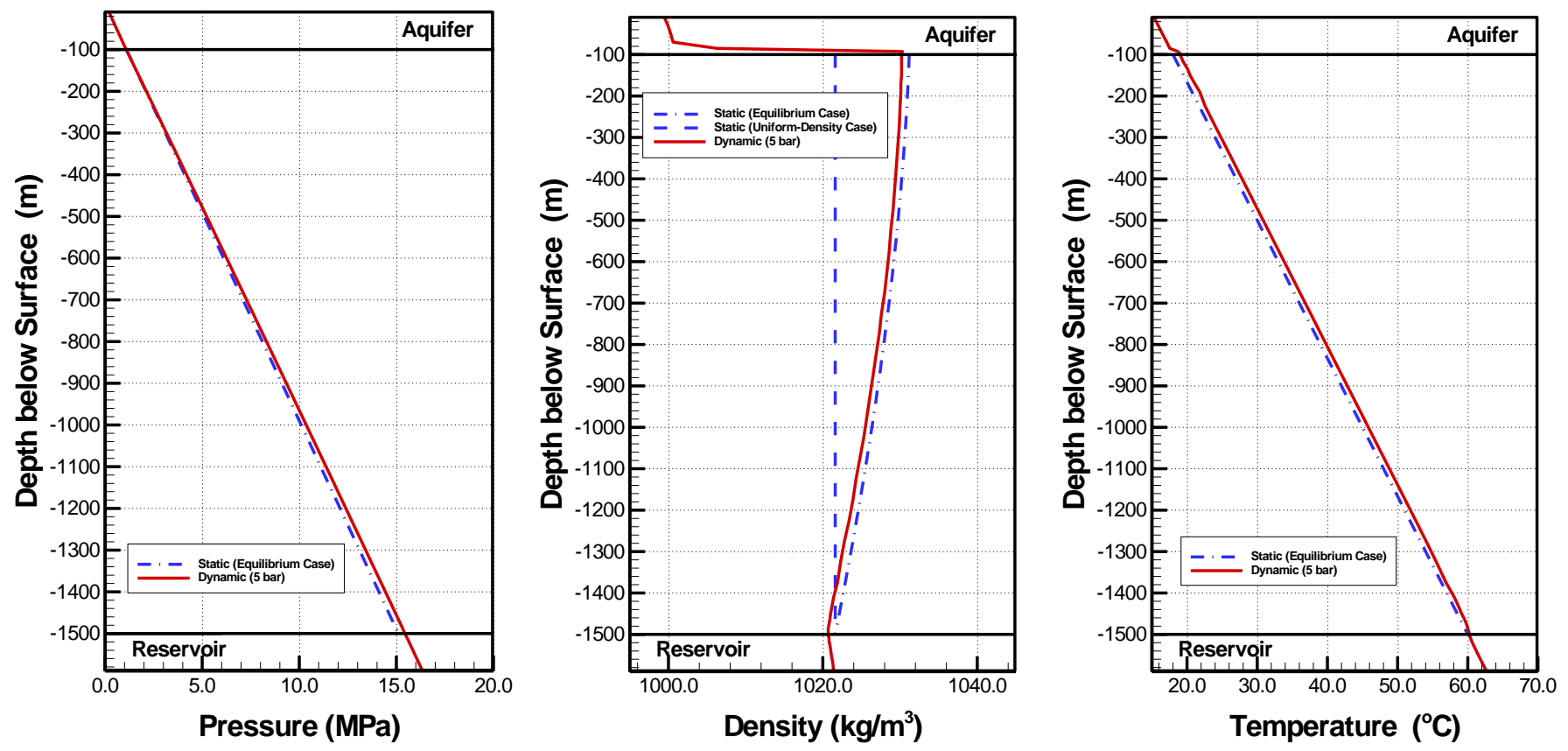

Figure 6: Vertical profiles of pressure, temperature, salinity, and density in the wellbore, for the low-salinity case. Results from the dynamic simulation are for a pressure increase of $0.5 \mathrm{Mpa}$. 


\subsubsection{Sensitivity to Wellbore Permeability}

Effective permeabilities of a leaking wellbore may vary over a wide range depending on the well condition (e.g., unplugged, plugs made of poor or degraded cement, mud-filled or debris-filled wells, etc.). In order to understand how this variation may affect threshold pressure and flow rates, we have simulated additional sensitivity cases with effective wellbore permeabilities of $10^{-6} \mathrm{~m}^{2}, 10^{-10} \mathrm{~m}^{2}$, and $10^{-12} \mathrm{~m}^{2}$. Figure 7 (a) shows brine flow rate as a function of time for the base case permeability $\left(10^{-8} \mathrm{~m}^{2}\right)$ as well as the three additional permeabilities. Results are shown for two different cases of reservoir pressure increase ( $0.5 \mathrm{MPa}$ and $0.2 \mathrm{MPa})$, one above and one below the threshold pressure identified in Section 3.2.1.

First we note that the transient behavior of wellbore flow as well as the flow magnitude vary strongly as a function of permeability. For the 0.5-MPa case, the long-term flow rates are about $3.6 \mathrm{~kg} / \mathrm{s}$ ( 82,000 gallon per day), $2.2 \times 10^{-2} \mathrm{~kg} / \mathrm{s}$ (500 gallon per day), 2.2 $\times 10^{-4} \mathrm{~kg} / \mathrm{s}$ (5 gallon/day), and $2.2 \times 10^{-6} \mathrm{~kg} / \mathrm{s}(0.05$ gallon/day), respectively, for wellbore permeabilities of $10^{-6} \mathrm{~m}^{2}, 10^{-8} \mathrm{~m}^{2}, 10^{-10} \mathrm{~m}^{2}$, and $10^{-12} \mathrm{~m}^{2}$. (That the permeability increase from $10^{-8} \mathrm{~m}^{2}$ to $10^{-6} \mathrm{~m}^{2}$ results in a flow rate increase by more than two orders of magnitude is a result of strong temperature changes in the wellbore fluids, as discussed in the next paragraph.) Despite these differences, the question whether sustainable flow occurs or not for a given pressure and salinity scenario is independent of wellbore permeability. All 0.5-MPa cases result in sustained flow over the entire simulation period, whereas all $0.2-\mathrm{MPa}$ cases show temporary brine migration up the well that ceases when a new equilibrium has been reached. 


\subsubsection{Temperature Effects}

We have briefly speculated in Section 3.2.1 that a large wellbore flow rate sustained over a long time period may lead to a non-negligible temperature increase in the adjacent shale formation, a result of the heat transported with the hot brine. Depending on its magnitude, such temperature increase might jeopardize the validity of the equilibrium assumption in the static calculations. In order to check this temperature dependence, we have plotted in Figure 7(b) the temperature evolution at the bottom of the aquifer for the four permeability cases and the two pressure-increase scenarios. Only one case-featuring the highest wellbore permeability in combination with a 0.5 -MPa pressure buildup - shows a strong temperature increase with time. Thus, temperature effects appear to be relevant only if high flow rates are sustained over a long period (i.e., if the threshold pressure is exceeded). In contrast, temperature is not or only temporarily affected as long as the reservoir pressure is below the threshold pressure, no matter what the wellbore permeability is. In other words, the threshold calculation using the static model with equilibrium assumption is generally accurate, for all cases of wellbore permeability. If, however, the threshold value is exceeded and long-term flow is sustained, the wellbore permeability will strongly affect the resulting flow rates up the well and will also define the rate at which the surrounding formation heats up in response to its contact with hot brine. 


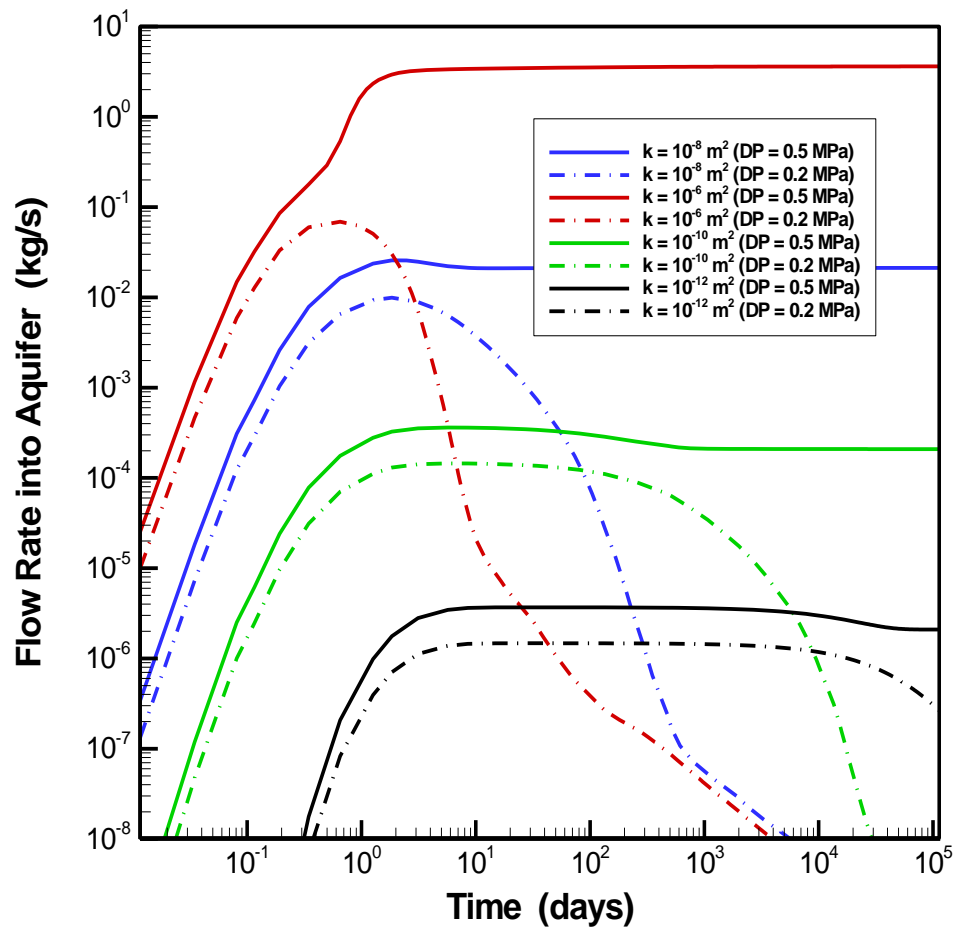

(a)

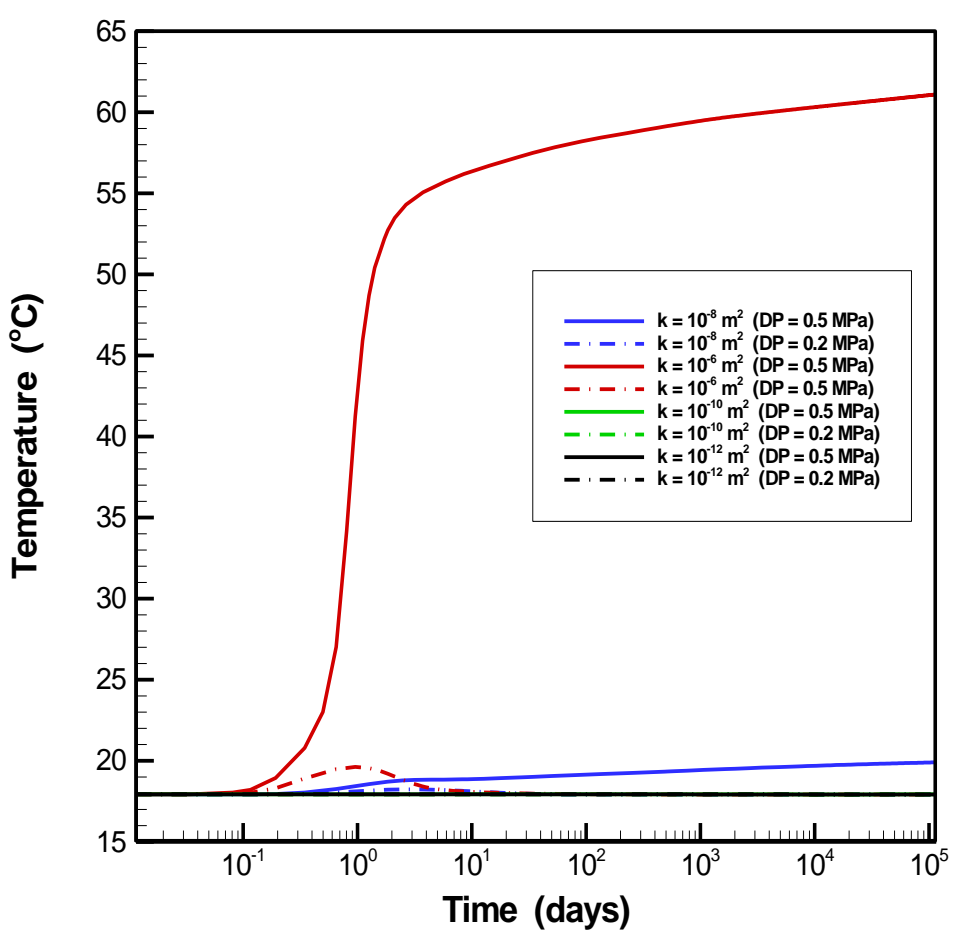

(b)

Figure 7: Evolution of (a) flow rate and (b) temperature in wellbore at the bottom of the freshwater aquifer, for four wellbore permeability cases and two pressure change values (above and below previously calculated pressure threshold), for the low-salinity case. DP refers to the pressure increase boundary condition in the brine reservoir. All green and black lines are on top of each other, as temperature effects are negligible. 


\section{Dynamic Evaluation of Brine Migration Outside of Casing}

Our previous simulations assume the potential for brine leakage within a well screened both in the freshwater aquifer and the injection reservoir. An arguably less conservative leakage scenario is that of brine flow through a vertical pathway outside of the well casing, for example through a small fracture zone that may have formed in the formation near the well as a result of drilling (Figure 8). In this case, the effective permeability of the vertical pathway is likely smaller, and the migrating brine may effectively interact with the formation, allowing for fluid and diffusive transport exchange in addition to heat transfer. The question arises whether such lateral exchange will affect the applicability of the static solutions for threshold pressure. We address this question conducting additional dynamic simulations for the scenario depicted in Figure 8. The following modeling assumptions are made:

- Brine flow occurs outside of the wellbore, in a vertical fracture zone.

- For better comparison with the leaking wellbore scenario, the cross-sectional area for flow within the fracture zone is equal to the cross-sectional area of the wellbore.

- The fracture zone is represented as a high-permeability feature. Three different cases are simulated with effective vertical permeability values of $10^{-8} \mathrm{~m}^{2}, 10^{-10} \mathrm{~m}^{2}$ and $10^{-12} \mathrm{~m}^{2}$, respectively. Again for better comparison, these values are chosen to be identical to three of the leaking wellbore scenarios discussed in Section 3.2.3. However, the higher permeability values of $10^{-8} \mathrm{~m}^{2}$ and $10^{-10} \mathrm{~m}^{2}$ are deemed less realistic (too high) for a fracture zone. 
- The vertical fracture zone is hydraulically connected to the adjacent formation, with horizontal permeability at the interface equal to formation permeability (i.e., $10^{-12} \mathrm{~m}^{2}$ for the injection reservoir and the shallow aquifer, and $10^{-18} \mathrm{~m}^{2}$ for the intervening shale). Diffusive and heat exchange also occur.

- The strata between the freshwater aquifer and the deep injection formation are entirely comprised of low-permeability shale. In other words, there is no intermediate aquifer which could function as a thief zone for upward migration of brine. Thief zones could significantly increase attenuation of brine (e.g., Nordbotten et al., 2004).

- The wellbore itself has no function in this simulation (i.e., assuming intact casing or properly functioning plugs).

- Unless otherwise noted, all model properties and boundary/initial conditions are identical to the base case simulations with open wellbore flow. Simulation results presented are for the low salinity case.

There are many other potential leakage scenarios associated with wells that are not considered here, such as vertical flow between the well casing and the well cement or vertical flow through degraded well cement (e.g., Gasda et al., 2004; Nordbotten et al., 2005). Selection of these scenarios affects the potential for and magnitude of lateral exchange with the formation. For example, if brine leakage would occur between casing and cement, the lateral exchange with the formation would be limited by the permeability of the cement. 


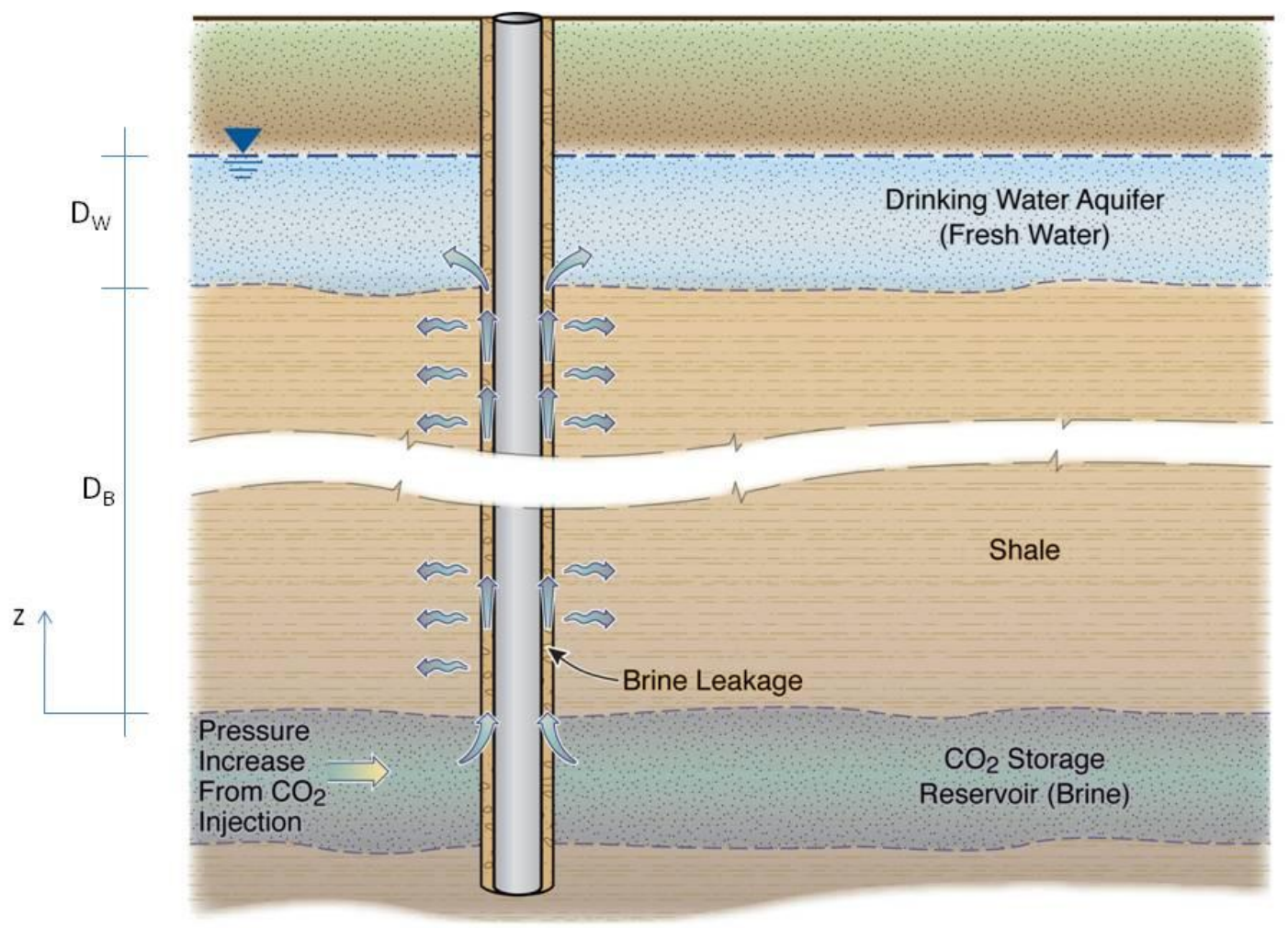

Figure 8: Schematic showing upward brine migration in fracture zone between well cement and the formation

Figures 9 and 10 show the resulting flow rates and salinity levels in the vertical fracture zone at the bottom of the freshwater aquifer, for pressure increases of $0.5 \mathrm{MPa}$ and 0.2 $\mathrm{MPa}$, respectively. As a reminder, we have established in Sections 2 and 3 that a pressure increase of $0.5 \mathrm{MPa}$ is above the threshold value for sustained brine flow, while a pressure increase of $0.2 \mathrm{MPa}$ is below the threshold value. We compare the three cases with fracture zone permeabilities of $10^{-8} \mathrm{~m}^{2}, 10^{-10} \mathrm{~m}^{2}$, and $10^{-12} \mathrm{~m}^{2}$, and for each case, we simulate brine migration with and without lateral fluid and mass exchange. The permeability cases without fluid and mass exchange are identical to the open wellbore cases studied in Section 3.2. 
As seen in the earlier results, the permeability of the leakage pathway has a strong impact on the long-term brine migration rate in the case where sustained brine flow occurs (Figure 9a). Less expectedly, the lateral flow and diffusive transport between the fracture zone and the shale formation can have an equally strong impact. At least for the case with an effective fracture zone permeability of $10^{-12} \mathrm{~m}^{2}$, the fluid exchange with the formation results in reduced and strongly delayed brine migration up the vertical pathway. The importance of lateral brine losses into the shale, despite very low shale permeability compared to the fracture zone permeability, is a result of the much larger cross-sectional area for lateral versus vertical flow and the relatively steep pressure gradients between the fracture zone and the formation.

The impact of lateral fluid and mass exchange on salinity values is even stronger, as diffusive exchange adds to advective transfer of dissolved solids between fracture zone and shale formation. We can see in Figure 9(b) that salinity increases show no delay in the $10^{-8}-\mathrm{m}^{2}$ case, are significantly retarded in the $10^{-10}-\mathrm{m}^{2}$ case, and end up to be zero in the $10^{-12}-\mathrm{m}^{2}$ case, even after a long simulation period of several hundred years. (Note: The period of increased pressure is likely not much longer than 50 to 100 years in typical geologic carbon sequestration projects.) It is obviously important to account for the interaction between the vertical pathway and the formation when evaluating the evolution and magnitude of brine migration from deep to shallow formations. The fluid and mass exchange with the surrounding formation can strongly reduce flow rates and salinity values, even if the intermediate strata in contact with the migrating brine are low- 
permeability shale. This mitigating effect would be stronger if a higher-permeability thief zone existed between the injection formation and the aquifer.

An interesting behavior is observed in Figure 10 for the 0.2-MPa pressure buildup. All cases without lateral fluid and mass transfer between the fracture zone and the shale formation show temporary migration of brine up the vertical pathway, but long-term sustained flow is not observed because the pressure increase of $0.2 \mathrm{MPa}$ is below the critical pressure. This behavior changes when the fracture zone interacts with its surroundings. Advective and diffusive transport from the migrating brine into the shale formation reduces the brine salinity and density in the vertical pathway. As a result, the threshold pressure is lower, to the extent that the pressure buildup of $0.2 \mathrm{MPa}$ in the injection formation is now sufficient to lift the heavier fluid column and to induce sustained flow, albeit at a small magnitude. Static models for calculations of threshold pressure can thus not be applied to leakage scenarios where lateral exchange of fluid and mass between the vertical pathway and the formation is relevant. 


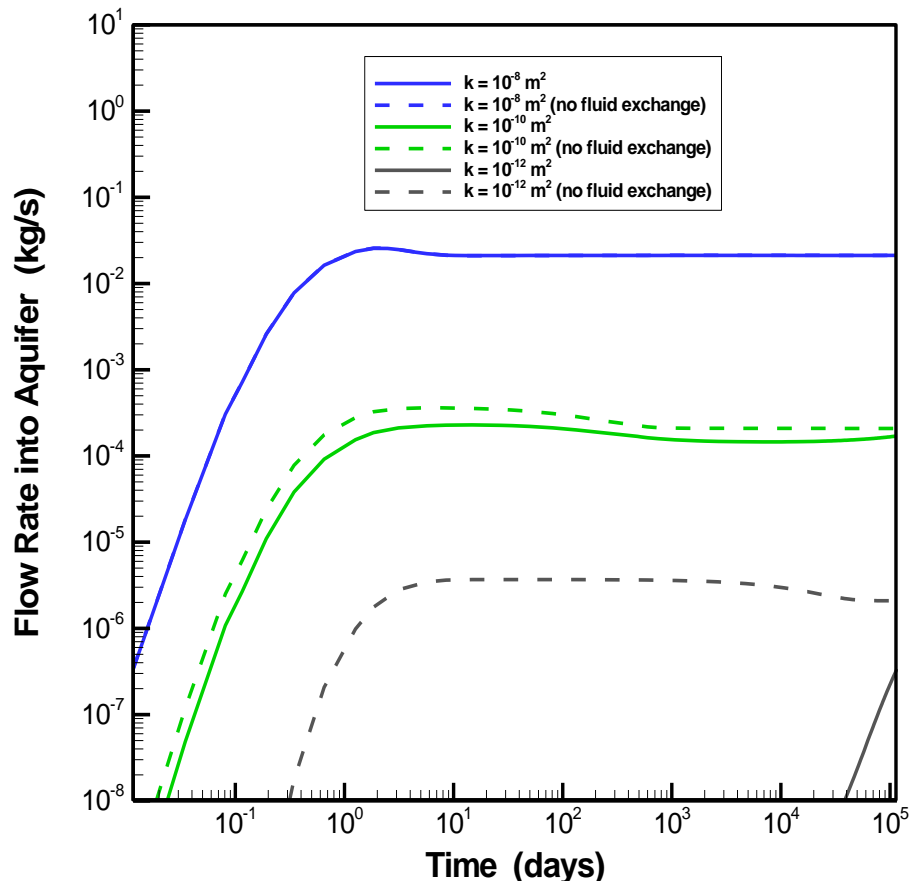

(a)

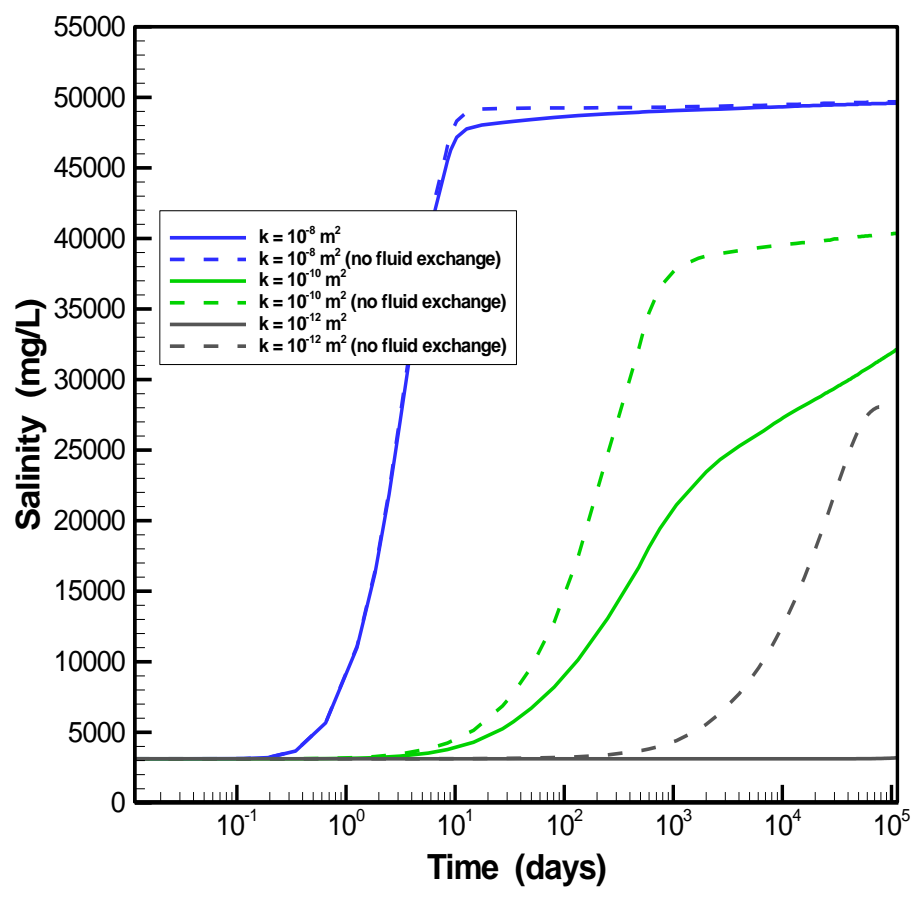

(b)

Figure 9: Evolution of (a) flow rate and (b) salinity in fracture zone between well cement and formation at the bottom of the freshwater aquifer, for the lowsalinity case. High, medium, and low permeability refer to permeability values of $10^{-8} \mathrm{~m}^{2}, 10^{-10} \mathrm{~m}^{2}$, and $10^{-12} \mathrm{~m}^{2}$. The pressure increase in the injection reservoir is $0.5 \mathrm{MPa}$. The solid and dashed blue lines for flow rate in the high-permeability case are on top of each other. 


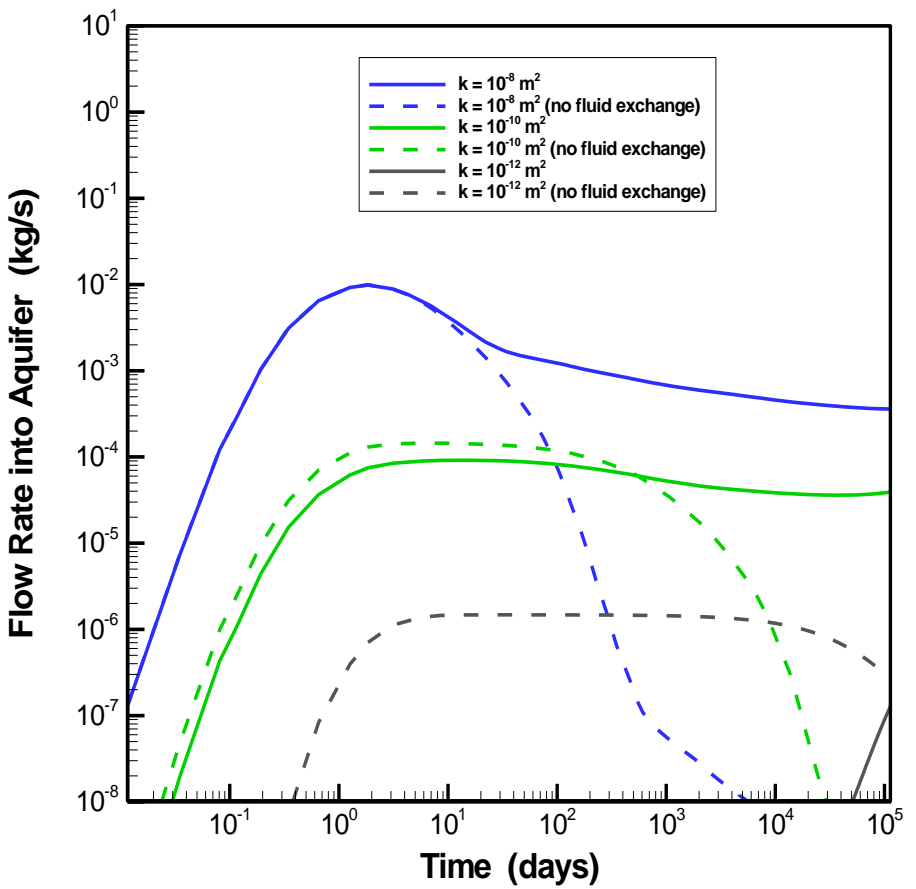

(a)

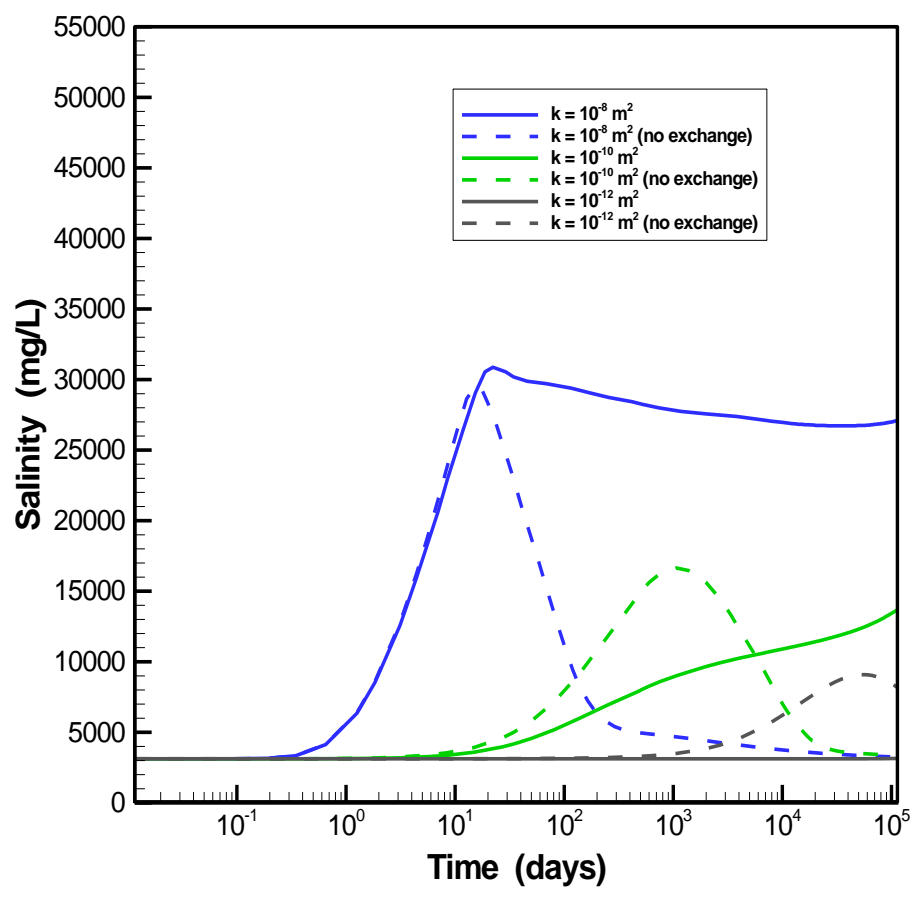

(b)

Figure 10: Evolution of (a) flow rate and (b) salinity in fracture zone between well cement and formation at the bottom of the freshwater aquifer, for the lowsalinity case. High, medium, and low permeability refer to permeability values of $10^{-8} \mathrm{~m}^{2}, 10^{-10} \mathrm{~m}^{2}$, and $10^{-12} \mathrm{~m}^{2}$. The pressure increase in the injection reservoir is $0.2 \mathrm{MPa}$. 


\section{Summary and Conclusions}

We have conducted non-isothermal brine flow simulations to evaluate the potential environmental impact of large-scale pressure increases expected from $\mathrm{CO}_{2}$ injection into deep saline reservoirs. If permeable conduits such as leaking wellbores connect the zone of elevated pressure with a shallow freshwater aquifer, the formation brines could be pushed upwards along these conduits and mix with overlying groundwater resources. Our simulation model is comprised of a vertical wellbore surrounded by an idealized layered sequence of formations, with, from top to bottom, a freshwater aquifer, a shale formation, and a deep saline reservoir. The system is initially at hydrostatic equilibrium; temperature and salinity increase linearly with depth. An instantaneous step-change in pressure is imposed in the saline reservoir at the boundary of the model domain, representing effects from distant $\mathrm{CO}_{2}$ injection, and the resulting potential for brine leakage is evaluated. Two conceptual models of wellbore flow are considered. The first model assumes that there is no exchange of fluid and/or salt between the leakage pathway and the adjacent shale (e.g., representing brine migration within the wellbore, and assuming impermeable casing). Main conclusions from this conceptual model are summarized below:

- The pressure rise in the injection reservoir drives dense water up the wellbore. Our dynamic simulations confirm, however, that such a pressure increase does not necessarily lead to sustained flow, since the brine being pushed upward has a higher density than the wellbore fluid it displaces. Sustained flow only occurs if the pressure rise is large enough to overcome the increased fluid column weight after full invasion of brine into the well up to the bottom of the freshwater aquifer. 
By conducting dynamic simulations for a range of pressure and salinity conditions, we have determined the critical threshold pressure that needs to be exceeded for sustained flow of dense brine up a well into a shallow freshwater aquifer.

- The dynamic simulations compare well with the static calculation method for threshold pressure developed by Nicot et al. (2008), who considered two bounding cases for the vertical density profile in the wellbore after brine intrusion: (1) an equilibrium case, in which brine density varies as a function of depth, under the assumption that the invading fluid instantaneously equilibrates thermally and hydraulically with its surroundings; and (2) a uniform-density case, in which density variation within the wellbore is neglected. Our dynamic models suggest that the static calculation combined with an equilibrium assumption provides an accurate estimate for threshold pressure. The threshold values obtained from the uniform-density assumption are less accurate, but easier to calculate and conservative compared to equilibrium values.

- The threshold pressure is independent of the hydraulic properties of wellbore and geologic formations. Once the threshold pressure is exceeded, however, the resulting brine flow is strongly dependent on hydraulic (and other) properties, in particular the effective permeability of the wellbore and the magnitude of pressure increase. The brine flow rate up the well is less than the comparable flow rate for a case without density stratification. 
The second conceptual model considered in this paper is that of brine flow through a vertical pathway outside of the cased well, for example in fractures or cracks that may form a permeable zone between the well cement and the formation. In this case the migrating brine slowly interacts with the adjacent low-permeability shale. Findings related to this conceptual model are as follows:

- The fluid and mass exchange with the surrounding formation can strongly reduce the brine flow rate up the leakage pathway into the shallow aquifer, even if the intermediate strata in contact with the migrating fluid comprise a lowpermeability medium such as a shale formation. The reduced brine flow rate correlates with an even more reduced salinity of the migrating brine, as diffusive exchange with the shale formation adds to advective transfer of dissolved solids. These mitigating effects would be exacerbated if a higher-permeability thief zone existed somewhere between the deep reservoir and the shallow aquifer.

- The static calculation methods for threshold pressure after Nicot et al. (2008) may not be adequate for well flow scenarios where lateral exchange of fluid and mass with the formation is relevant. Such lateral exchange reduces the brine salinity and, consequently, the weight of the fluid column in the conduit, thereby reducing the formation pressure buildup necessary to induce sustained flow. In cases where the static calculations are not adequate, the threshold pressure evaluation can be conducted with a dynamic model that accounts for the transfer of fluid and dissolved solids with the surrounding formation. 
The focus in this paper is mostly on the determination of threshold pressure for sustained brine flow, to understand controlling parameters and to evaluate the applicability of simple static calculation methods. In future work, we will conduct a thorough evaluation of the resulting brine flow rates for a wider range of conditions, including additional scenarios such as considering an intermediate-level thief zone or assuming a finite time for pressure increase in the saline reservoir. We furthermore plan to compare our simplified simulation model for flow in an open wellbore (i.e., Darcy flow in a highpermeability feature) with an improved Navier-Stokes wellbore model (e.g., Pan et al., 2008).

\section{Acknowledgment}

The authors wish to thank two anonymous reviewers as well as Lehua Pan of Lawrence Berkeley National Laboratory for a careful review of the manuscript and the suggestion of improvements. This paper has also been reviewed in accordance with the U.S.

Environmental Protection Agency's peer and administrative review policies and approved for publication. Mention of trade names or commercial products does not constitute endorsement or recommendation for use. This work was funded in part by the US Environmental Protection Agency, Office of Water and Office of Air and Radiation, under an Interagency Agreement with the U.S. Department of Energy at the Lawrence Berkeley National Laboratory. Supplementary funding was provided by the Assistant Secretary for Fossil Energy, Office of Sequestration, Hydrogen, and Clean Coal Fuels, National Energy Technology Laboratory, of the U.S. Department of Energy, DE-AC0205CH11231. Research was performed while Karl Bandilla held a National Research Council Research 
Associateship Award at US EPA's Ecosystems Research Division of the National Exposure Research Laboratory.

\section{References}

Apps, J., Zheng, L., Zhang, Y., Xu, T., Birkholzer, J.T., 2010. Evaluation of Groundwater Chemistry Changes in Response to CO2 Leakage from Deep Geological Storage, Transport in Porous Media, 82(1), pp. 215-246.

Bachu, S., 2008. $\mathrm{CO}_{2}$ Storage in Geological Media: Role, Means, Status and Barriers to Deployment, Progress in Energy and Combustion Science, Vol. 34, pp. 254-273.

Baines, S.J., Worden, R.H., 2004. Geological Storage of Carbon Dioxide, in: S.J. Baines and R.H. Worden (eds.), Geological Storage of Carbon Dioxide, Geological Society, London, Special Publications, Vol. 233.

Birkholzer, J.T., Zhou, Q., Tsang, C.F., 2009. Large-scale impact of $\mathrm{CO}_{2}$ storage in deep saline aquifers: a sensitivity study on the pressure response in stratified systems, International Journal of Greenhouse Gas Control, 3(2), 181-194.

Birkholzer, J.T., Zhou, Q., 2009. Basin-Scale Hydrogeologic Impacts of $\mathrm{CO}_{2}$ Storage: Capacity and Regulatory Implications, International Journal of Greenhouse Gas Control, 3(6), pp. 745-756.

Dooley, J.J., Kim, S.H., Edmonds, J.A., Friedman, S.J., Wise, M.A., 2004. A First-Order Global Geological $\mathrm{CO}_{2}$-Storage Potential Supply Curve and its Application in a Global Integrated Assessment Model, in Proceedings 7th International Conference on Greenhouse Gas Control Technologies, Vancouver, Canada. September 5-9. 
Gasda, S.E., Bachu, S., Celia, M.A., 2004. Spatial characterization of the location of potentially leaky wells penetrating a deep saline aquifer in a mature sedimentary basin, Environmental Geology, 46, pp. 707-720.

IPCC (Intergovernmental Panel on Climate Change), Special Report on Carbon Dioxide Capture and Storage, 2005.

Kharaka, Y.K., Thordsen, J.J., Kakouros, E., Ambats, G., Herkelrath, W.N., Beers, S.R., Birkholzer, J.T., Apps, J.A., Spycher, N.F., Zheng, L., Trautz, R.C. Rauch, H.W., Gullickson, K., 2010. Changes in the Chemistry of Shallow Groundwater Related to the 2008 Injection of CO2 at the ZERT Field Site, Bozeman, Montana, Environmental Earth Sciences, 60(2), pp. 273-284, doi: 10.1007/s12665-009-0401-1.

NETL (National Energy Technology Laboratory), 2010. Best Practices for Site Screening, Selection, and Initial Characterization for Storage of $\mathrm{CO}_{2}$ in Deep Geologic Formations, NETL Report DOE/NETL-401/090808, November 2010.

Nicot, J.P., 2008. Evaluation of large-scale carbon storage on fresh-water section of aquifers: A Texas study, International Journal of Greenhouse Gas Control, 2(4), $582-593$.

Nicot, J.P., Oldenburg, C.M., Bryant, S.L., Hovorka, S.D., 2008. Pressure perturbations from geologic carbon sequestration: area-of-review boundaries and borehole leakage driving forces, in Proceedings $9^{\text {th }}$ International Conference of Greenhouse Gas Control Technologies, Washington, USA, November 2008.

Nordbotten, J.M., Celia, M.A., Bachu, S., 2004. Analytical solutions for leakage rates through abandoned wells, Water Resources Research, 40, W04204. 
Nordbotten, J. M., Celia, M. A., Bachu, S., Dahle, H. K., 2005. Semianalytical solution for $\mathrm{CO}_{2}$ leakage through an abandoned well, Environmental Science and Technology, 39 (2), 602-611.

Oldenburg, C.M., Rinaldi, A.P., 2010. Dynamics of Upward Brine Displacement Caused by $\mathrm{CO}_{2}$ Injection, Abstract in Proceedings $9^{\text {th }}$ Annual Conference on Carbon Capture and Sequestration, Pittsburgh, PA, May 10-13, 2010.

Pan, L., Oldenburg, C.M., Wu, Y.-S., Pruess, K., 2008. Wellbore flow model for carbon dioxide and brine, in Proceedings $9^{\text {th }}$ International Conference of Greenhouse Gas Control Technologies, Washington, USA, November 2008.

Pruess, K., 2008a. On $\mathrm{CO}_{2}$ Fluid Flow and Heat Transfer Behavior in the Subsurface, Following Leakage from a Geologic Storage Reservoir, Environmental Geology, Vol. 54, No. 8, pp. 1677-1686, DOI 10.1007/s00254-007-0945-x.

Pruess, K., 2008b. Leakage of $\mathrm{CO}_{2}$ from Geologic Storage: Role of Secondary Accumulation at Shallow Depth, International Journal of Greenhouse Gas Control, Vol. 2, Issue 1, pp. 37-46, doi:10.1016/S1750-5836(07)00095-3.

Pruess, K., Oldenburg, C., Moridis, G., 1999. TOUGH2 User’s Guide. Report LBNL43134, Lawrence Berkeley National Laboratory, Berkeley, CA, USA.

Tsang, C.F., J. Birkholzer and J. Rutqvist., 2008. A Comparative Review of Hydrologic Issues Involved in Geologic Storage of CO2 and Injection Disposal of Liquid Waste, Environmental Geology, Vol. 54, No. 8, pp. 1723-1737, DOI 10.1007/s00254-0070949-6. 
USEPA (United States Environmental Protection Agency), 2002.Technical Program Overview Underground Injection Control Regulations, Office of Water Report 4606 EPA 816-R-02-025, December 2002.

USEPA (United States Environmental Protection Agency), 2008. Federal Requirements under the Underground Injection Control (UIC) Program for Carbon Dioxide $\left(\mathrm{CO}_{2}\right)$ Geologic Sequestration (GS) Wells, Proposed Rule, 40 CFR Parts 144 and 146, EPA-HQ-OW-2008-0390, available online at http://www.epa.gov/fedrgstr/EPA-

\section{WATER/2008/July/Day-25/w16626.htm}

Yamamoto, H., Zhang, K., Karasaki, K., Marui, A., Uehara, H., and Nishikawa. N., 2009. Numerical investigation concerning the impact of $\mathrm{CO}_{2}$ geologic storage on regional groundwater flow, International Journal of Greenhouse Gas Control, 3(5), 586-599. Zhou, Q., Birkholzer, J.T., Tsang, C.F., Rutqvist, J., 2008. A method for quick assessment of $\mathrm{CO}_{2}$ storage capacity in closed and semi-closed saline formations, International Journal of Greenhouse Gas Control, 2(4), 626-639.

Zhou, Q., Birkholzer, J.T., Mehnert, E., Lin, Y.-F., Zhang, K., 2010. Modeling Basin- and Plume-Scale Processes of $\mathrm{CO}_{2}$ Storage for Full-Scale Deployment, Ground Water, 48(4), pp. 494-514. 


\section{DISCLAIMER}

This document was prepared as an account of work sponsored by the United States Government. While this document is believed to contain correct information, neither the United States Government nor any agency thereof, nor The Regents of the University of California, nor any of their employees, makes any warranty, express or implied, or assumes any legal responsibility for the accuracy, completeness, or usefulness of any information, apparatus, product, or process disclosed, or represents that its use would not infringe privately owned rights. Reference herein to any specific commercial product, process, or service by its trade name, trademark, manufacturer, or otherwise, does not necessarily constitute or imply its endorsement, recommendation, or favoring by the United States Government or any agency thereof, or The Regents of the University of California. The views and opinions of authors expressed herein do not necessarily state or reflect those of the United States Government or any agency thereof or The Regents of the University of California.

Ernest Orlando Lawrence Berkeley National Laboratory is an equal opportunity employer. 